the patients themselves, carefully look around and select whom they think is the most competent; men who never think of self but of the good of the patient, who never ask for percentage but ask that the patient have the best care. I have any number of such noble friends, who eontinually send good paving patients th me and for whom I have never been alble to do any favor. I often feel guilty, but some time hope to recipiocate, and be able tn do them favors.

[ take special pains to instruct the patients to return to the physician who sent them to me, for after-treatment, often giving them a note or sending a letter direct. It happens, however, occasionally, that the patients do not want to re. turn. They have become vexed at something, and think they have been neglected. They have all kinds of notions. I am obliged to defend the physician and insist that they return for after-treatment. Thus I try to uphold the reputation of the general practitioner and save his patients to him. I try to be a real specialist.

In the meantime, I try to keep up the good work, and hope that the time will come again, when this wild struggle for the mighty dollar will lessen, and men will be gauged by the good deeds they do, by their mental capacity and not by the amount of money they can make.

Your truly,

J. H. Carstens, M.D.

\section{National Therapeutic Society.}

Washington, D. C., April 16, 1900.

To the Editor:-The attention of the Therapeutic Society of the District of Columbia having been called, through several articles recently published, to the formation of a national therapeutic society, at a recent meeting it was decided to take the initiative steps, with representatives of other therapeutic societies, looking toward the formation of such a national body. I have been instructed to ask that THe JourNaL aid us in this movement. We would suggest that all therapeutic societies, or as many as desire, throughout the United States, elect and send delegates, with such an object in view, to meet in this eity, May 1-4, at the time of the meeting of the Association of American Physicians. The Eighth Decennial Convention for Revision of the U. S. Pharmacopeia holds its session here at the same time. The D. C. Therapeutic Society will be pleased to meet all such delegates at the medical department, National University, No. 1328 I Street, N. W. on Tuesday, May 1, 3 p. m., to take preliminary steps in this direction.

D. Olin Leech, M. D., Corresponding Secretary, Therapeutic Society, District of Columbia.

Paris and the Midnight Sun.

Members of the Association who intend crossing the At lantic to be present at the Thirtieth International Medical Congress should read the following, which explains itself :

War Department, Strrgeon-General's Office.

Washungtor, D. C., April 13, 1900

Henry Gaze \& Sons, 113 Broadway, New YokK, N. Y.

Gentlemen: I have received your circular headed "Paris and the Midnight Sun" and stating that in committee has been organized to arrange for this trip. Will you kindly inform me by what authority my name has been included among the mem bers of this committee? I have no knowledge of my appointment upon such a committee, or of such a committee having met to consider the matter referred to, and I have no intention of making the trip which you advertise.

Very truly yours,

GEo. M. Sternberg, Surgeon-General, L. S. Army.

\section{Assoctation 2lews.}

The Official Program.-In order to avoid misunderstand ings and to protect the interests of advertisers, attention is called to the fact that there is but one official program. This program is copyrighted by the 33oard of Trustees and contains no advertising matter.

Section on Obstetrics and Diseases of Women.-The program of this Section is now full. Wednesday morning, June 6, will be given up to a "Symposium on Obstetrics;" Wednes- day afternoon to one on "The Relation of Pelvic and IntraAbdominal Diseases to Nervous Diseases." Thursday morning, June 7, will be devoted to the subject of "Cancer of the Fe. male Generative Organs, Including the Breast;" Thursday afternoon to "Inflammatory Diseases of the Female Genitalia." The afternoon of Tuesday, June 5, and the morning of Friday, $J$ une 8 , will be devoted to general papers.

Amendments to Constitution.-The following was offered by Dr. Dudley S. Reynolds, Louisville, Ky., at the last meeting of the Association: Proposition to amend Article 2 of the Constitution, by adding to the qualifications of membership in those societies eligible to send delegates to this Association. After the words "Marine Hospital Service of the United States," at the conclusion of the second paragraph; provided, however, that no State, county or other auxiliary body sending representatives shall receive into its membership any one who may after 1900 have received the degree of Ioctor of Medicine on less than four years of graded instruction or an equivalent rerequirement (laid over for one year).

Committee on National Legislation.-Attention is again directed to the call to the National Legislative Conference of the Association, to be held in Washington, May 1 and 2 (see The Journal, April 21, p. 1019). The Chairman of the Committee on Arrangements of the Congress of American Physicians and Surgeons has extended an invitation to members of the National Legislative Conference to be guests of the Congress during the May meeting. Those wishing to accept this courtesy should call at the Bureau of Registration, in the Arlington Hotel, on their arrival in Washington, and on registration they will also receive cards to the reception, to the smoker to be given by the Cosmos Club on the evening of May 1 , and the program for the meetings of the Congress. Accord. ing to the by-laws, a physician may be aceredited as a visitor by any one of the constituent societies and the certificate of the secretary of one of the societies that he is thus accredited will enable him to register on payment of the registration fee, but not to take part in the deliberations of the Congress.

Railroad Rates for Atlantic City Meeting.-The Committee on Transportation, of the American Medical $\Lambda$ ssociaTION, reports that the Trunk Lines Association has granted one-fare and one-third on the certificate plan, as the rate for the meeting in June. Tickets will be on sale in territory of these lines at this rate from May 30 to June 7 , and are good to return to June 23. The Trunk Lines Association has invited the other railroad associations to concur in the rate and time limit. The Committee has been very much taxed in answering communications from nearly every section of the country suggesting means for securing a one-fare rate for the round trip on this occasion, and has adopted every expediency for securing the one-fare rate, but has been unable to obtain it. For the information of many of those who have written recently on this subject, we quote from the final communication from the Trunk Lines Association, dated April 4. After announcing the rate and time limit above noted, the secretary adds: "It is noted that you say it is still claimed by many, that the reduction of one fare should be granted for your meeting. I may state that your application has been twice before the Committee, and any greater reduction than fare and one-third on certifieate could not consistently be granted; it would be a discrimination against other bodies." When the other railroad associations act on the rate, etc., of the trunk lines, the committee will make a full report announcing the rates throughout the states. H. L. E. Johrson, M.D., Chairman.

Section Headquarters at Atlantic City.-Following is a correct list of the hotels sclected as headquarters for the different Sections. These hotels, with two exceptions, are all located on the board walk, directly fronting the ocean, and are considered the best hotels. Every effort will be made by the proprietors and their managers to furnish proper and pleasant ac commodations to all who elect to stop with them. Each Section has been located separately, with a view of avoiding the crowding and general annoyance that has characterized a num ber of the previous meetings. The hotels are all well located 